\title{
Uso de indicadores de saneamento ambiental, na bacia hidrográfica do Tucunduba, visando a redução das doenças de veiculação hídrica
}

Este trabalho teve como foco central o levantamento de indicadores de Saneamento Ambiental e Saúde em uma microárea da bacia Hidrográfica do Tucunduba para, com base nesses indicadores, auxiliar no planejamento de políticas públicas de saneamento e saúde e assim melhorar a qualidade de vida daquela comunidade, tendo em vista, que a mesma sofre há anos com a falta de serviços básicos de saneamento; para isso foi feita uma pesquisa de campo, levantando dados socioambientais fazendo uma associação desses dados com a situação do Saneamento inadequado, refletindo nos problemas de saúde enfrentados corriqueiramente por todos os moradores da referida área. Paralelamente, foi desenvolvido juntamente com a Secretaria de Estado de Desenvolvimento Urbano e Obras Públicas (SEDOP), ações de educação ambiental através de palestras aplicadas na comunidade buscando alcançar o maior público possível e a conscientização de todos, mostrando exemplos da rotina vivida diariamente, inserindo-os no contexto dos assuntos abordados para uma maior conscientização e assim demonstrar que cada um, com mudança de hábitos a atitudes, pode fazer parte da solução dos problemas relacionados à saúde e bem estar de todos.

Palavras-chave: Saneamento ambiental; Indicadores; Saúde Pública; Educação ambiental.

\section{Use of environmental sanitation indicators, in the Tucunduba hydrographic basin, aiming at the reduction of water-based diseases}

This work had as its central focus the survey of indicators of Environmental Sanitation and Health in a micro area of the Tucunduba River Basin. Based on these indicators, assist in the planning of public health and sanity policies and improve the quality of life of that community, bearing in mind that it has been suffering for years from the lack of minimum sanitation services. A field survey was carried out, raising social and environmental data, making an association of these data with the situation of inadequate Sanitation, reflecting the health problems faced by all residents of that area. At the same time, environmental education actions were developed, together with the State Department of Urban Development and Public Works (SEDOP), through lectures applied in the community. The task seeked to reach the widest possible audience and awareness of all, showing examples of the routine lived daily, in the context of the issues raised for greater awareness, demonstrate that each one, with a change of habits to attitudes, can be part of the solution of their problems related to the health and well-being of all.

Keywords: Environmental sanitation; Indicators; Public health; Environmental education.

Topic: Desenvolvimento, Sustentabilidade e Meio Ambiente

Reviewed anonymously in the process of blind peer
Received: 04/12/2020

Approved: 21/02/2021
Maria do Socorro Bezerra Lopes (id

Instituto Federal do Pará, Brasil

http://lattes.cnpq.br/1850698138869190

http://orcid.org/0000-0003-1650-4724

soclopes@gmail.com

William Rodrigues Pontes (i)

Instituto Federal do Pará, Brasil

http://lattes.cnpq.br/0048199136321186

http://orcid.org/0000-0001-7822-5988

wr214458@gmail.com

Adelan Nunes da Costa

Instituto Federal do Pará, Brasil

http://lattes.cnpq.br/9869195510309939

http://orcid.org/0000-0002-9817-269X

adelancosta@gmail.com

\author{
Márcia Valéria Porto de Oliveira Cunha (iD \\ Instituto Federal do Pará, Brasil \\ http://lattes.cnpq.br/3314512875867844 \\ http://orcid.org/0000-0003-3728-0977 \\ mv cunha@yahoo.com.br \\ Andrea Fagundes Ferreira Chaves \\ Instituto Federal do Pará, Brasil \\ http://lattes.cnpq.br/0962841142993635 \\ http://orcid.org/0000-0001-5528-2947 \\ engefag@yahoo.com.br \\ David Franco Lopes (iD \\ Universidade Federal do Pará, Brasil \\ http://lattes.cnpq.br/4561329364320659 \\ http://orcid.org/0000-0002-5228-4418 \\ davidlopes.1978@gmail.com
}

Referencing this:

LOPES, M. S. B.; PONTES, W. R.; COSTA, A. N.; CUNHA, M. V. P. O.; CHAVES, A. F. F.; LOPES, D. F.. Uso de indicadores de saneamento ambiental, na bacia hidrográfica do Tucunduba, visando a redução das doenças de veiculação hídrica. Nature and Conservation, v.14, n.1, p.107-115, 2021. DOI: http://doi.org/10.6008/CBPC2318-

2881.2021.001.0012 


\section{INTRODUÇÃO}

A história da humanidade, desde seus primórdios, está repleta de fatos que demonstram os problemas enfrentados no que diz respeito às doenças de veiculação hídrica; e que se estendem até os dias de hoje com uma verdadeira batalha, tendo como atores principais o poder público e as populações atingidas por esses males, sendo que essa problemática fica mais latente em locais cujo os serviços de saneamento são inexistentes ou deficitários.

O adensamento urbano na bacia do Tucunduba levou a alterações como retificação, canalização e aterramento que provocam modificações nos processos geomorfológicos a partir da alteração de etapas do ciclo hidrológico, como a infiltração e o escoamento superficial. As modificações geradas pela urbanização, como impermeabilização das vertentes do setor norte da bacia, aterramento nas áreas mais baixas levam a alagamentos constantes no período chuvoso em toda a área da bacia ocupada por canais, levando dezenas de pessoas a conviver com transbordamentos diários, permanência de água estagnada, entre outras condições que geram graves problemas de risco social e ambiental (CRISTO et al., 2014).

No aspecto físico, a área do Tucunduba se apresenta semelhante a um arco, de um lado ocupado por casas de alvenaria e do outro, por instituições com vegetação típica, sendo circundada por palafitas acessíveis através de estivas e passagem de aterro. Nas áreas de várzea do Tucunduba se manifestam vários níveis de degradação ambiental produzidos principalmente pelo adensamento populacional, pelo tipo de aterro e pela maneira como é feita as planícies holocênicas, pelo lançamento de lixo e esgoto no solo e nos canais de drenagem; promovendo uma obstrução de drenagem natural. Esses níveis de degradação vão desde a contaminação da água do igarapé, do lençol freático e do solo até a exposição de depósito de dejetos e a propagação de doenças (LUZ et al., 2014).

Buscando avaliar as condições da saúde e do saneamento básico, diversos pesquisadores se utilizam de indicadores de saneamento e de saúde, os quais também podem ser operados na tentativa de quantificar um índice de saneamento ou mesmo índices de saúde ambiental de determinada área de estudo. Os indicadores são normalmente utilizados como pré-tratamento aos dados originais e os índices correspondem a um nível superior de agregação (CHAVES et al., 2013).

O Objetivo Geral deste trabalho foi de conhecer fatores de riscos à saúde, utilizando indicadores relacionados ao Saneamento Ambiental e identificar as causas do surgimento de doenças de veiculação hídrica, na população pertencente a uma microárea do entorno do canal do Tucunduba. Tendo como objetivos específicos: Sensibilizar a população local sobre Saneamento e Educação Ambiental e os possíveis fatores de riscos ambientais e a saúde em uma área de expansão urbana; identificar riscos socioambientais e indicadores relacionados ao Saneamento Ambiental inadequado e ineficiente no local de estudo, capazes de influenciar a saúde da população. 


\section{MATERIAIS E MÉTODOS}

\section{Característica da Pesquisa}

A grande maioria dos indicadores desenvolvidos tem privilegiado a base de dados quantitativa e as análises em modelos matemáticos, o que representa uma limitação diante da dimensão subjetiva da qualidade ambiental. Além da dimensão objetiva, passível de ser avaliada por métodos quantitativos, a qualidade de um ambiente tem componentes subjetivos que exigem métodos no campo da avaliação qualitativa e da pesquisa social. O componente subjetivo remete à necessidade de se incorporar a perspectiva de quem vivencia aquela qualidade que se quer avaliar. A qualidade do ambiente na sua subjetividade remete, portanto, à sensação de conforto e bem-estar, algo que não pode ser medido, mas sim sentido de forma diferenciada por indivíduos e grupos de indivíduos. Essa sensação varia ao longo do tempo e do espaço em função de aspectos predominantemente culturais, além de econômicos, físicos e sociais (BORJA et al., 2003; CASTRO, 2016).

Enfim, a questão da qualidade está impregnada de subjetividade - da qual, por si só, os números e as estatísticas elaborados na perspectiva de técnicos e administradores não podem dar conta. É certo, porém, que indicadores quantitativos e modelos matemáticos contribuem para os aspectos objetivos da avaliação e para a composição de indicadores mistos (qualitativos e quantitativos) (BORJA et al., 2003; CASTRO, 2016).

A pesquisa realizada caracterizou-se por ser quali-quantitativa, que caracteriza-se por envolver métodos quantitativos e qualitativos para a obtenção de uma análise mais profunda do assunto da pesquisa, com o intuito de levantar indicadores de saneamento e saúde, de uma microárea dentro da área de pesquisa, quantificando percentualmente esses indicadores e associá-los as condições de saneamento e saúde da população que mora nas imediações do canal do Tucunduba dando suporte às políticas públicas de Educação Ambiental e Saúde.

Para o desenvolvimento da pesquisa teve-se a parceria institucional e apoio técnico operacional, entre o IFPA- Instituto Federal de Educação Ciência e Tecnologia do Pará, representado pela Coordenação de Saneamento, e a SEDOP- Secretaria de Estado de Desenvolvimento Urbano e Obras Públicas do Pará. Entretanto, para a realização da obra no Tucunduba a SEDOP possui alguns parceiros: Diretoria de Mobilização e Articulação Comunitária - DMAC, Coordenação de Trabalho Técnico Social - CTTS, entre outras empresas responsáveis pelas obras de engenharias desse projeto. A pesquisa foi realizada no período de Agosto de 2018 à Janeiro de 2019.

\section{RESULTADOS E DISCUSSÃO}

\section{Visitas Técnicas}

O trabalho foi iniciado com três visitas técnicas, que foram realizadas para o reconhecimento da área, servindo para comprovar a falta de infraestrutura urbana e de serviços de saneamento básico adequados para atender a população local como drenagem, esgotamento sanitário, água encanada e coleta de lixo, eram bastante precários, devido à alta concentração de habitações do tipo 'palafitas', ao longo do canal, afetando 
de forma direta a qualidade de vida da população, fato evidenciado na Figura 1 contribuindo para os constantes alagamentos e demais transtornos causados em parte dos bairros que integram a referida Bacia.

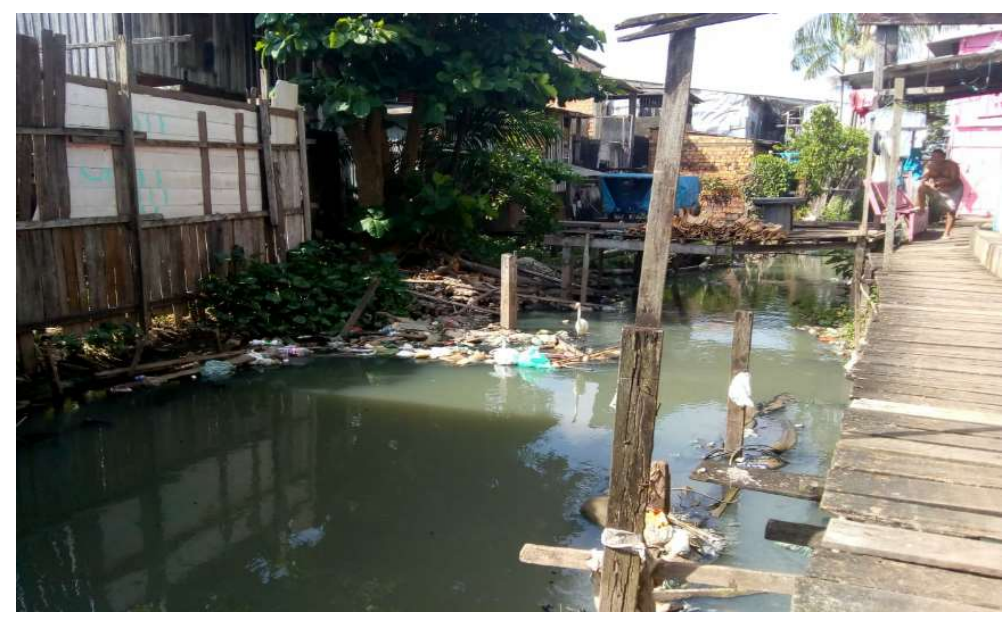

Figura 1: Resíduos sólidos irregulares no canal.

\section{Apresentação de Palestras}

As técnicas da SEDOP deram início à atividade, se pronunciando aos presentes, onde na ocasião agradeceram a presença de todos, bem como destacaram a importância da capacitação no tocante ao projeto, visto a importância da comissão para o melhor desenvolvimento das ações. Em seguida a técnica Mylene Souza distribuiu o material pedagógico, juntamente com as técnicas da empresa Urbaniza, aos membros presentes, para que assim todos pudessem acompanhar a explanação da instrutora, reforçando assim o processo de aprendizagem. A elaboração de material pedagógico foi feita em parceria com a SEDOP juntamente com a empresa Urbaniza, que é a empresa contratada para executar as ações do PTTS e colaboração dos alunos do IFPA (Adelan Nunes e William Pontes), sendo que este material de fundamental importância ajudou nos encontros realizados a fixar os temas abordados, facilitando a compreensão e comunicação entre todos os participantes do evento.

Dessa forma, a atividade foi iniciada pelo modulo I, que tratou de esclarecer as atribuições e competências dos membros da comissão, onde foram destacadas a importância das lideranças para o sucesso do andamento das atividades, das vistorias técnicas em área, assim como das consequências e dos impactos sociais advindos da obra. No modulo II, abordou-se acerca da comunicação e da articulação das parcerias, da produção de projetos, onde foram levantados os seguintes temas: Linguagem formal e informal, dicas para o planejamento de uma apresentação oral, acerca dos relatórios e documentos oficiais, articulação de parcerias, e captação de recursos.

Nesse sentindo, os membros presentes tiveram a oportunidade de conhecer a fundo tais temas, assim como usufruíram, em todos os momentos de poder se colocar, discutir e debater, com a instrutora e os demais membros presentes, realizando apontamentos relevantes, e questionamentos, permitindo que a atividade se tornasse interativa e prazerosa, facilitando assim, o processo ensino-aprendizagem. Destaca-se como fundamental para as organizações de moradores, as ações discutidas no primeiro momento com os membros, sendo elas: a) acompanhar as atividades do projeto de engenharia e do projeto social; b) atuar 
como disseminadores das informações obtidas em reuniões, orientações e visitas técnicas em área; c) trabalhar em prol da comunidade, fornecendo informações relevantes e fortalecendo a participação comunitária; d) unir e organizar os moradores para fins comuns; e) incentivar a comunidade a ir em busca de seus direitos; f) reforçar o exercício da cidadania; g) reunir, se possível com a comunidade a fim de promover reuniões e debates visando proporcionar momentos para o repasse de informações, mantendo todos informados sobre o andamento do projeto.

Passando para o segundo momento da capacitação, a instrutora Denise Oliveira, auxiliada pela Técnica Carla Silva, iniciou a atividade, apresentando a todos o aluno do IFPA do curso de Tecnologia em Saneamento William Rodrigues, que finalizou a segunda etapa do momento da capacitação - explicando os módulos III e IV, levando a temática preservação ambiental, fazendo um link com o tema saúde e saneamento.

Esses impactos são intensificados pela falta de saneamento básico, que muitas comunidades enfrentam diariamente, ocasionando assim, diversas doenças a essas populações que se encontram residindo nas periferias das grandes cidades. Com o auxílio da apresentação em slides e do material didático, o aluno do IFPA desenvolveu a atividade, buscando relacionar a temática com a realidade dos participantes, objetivando trazê-los para mais próximo dos assuntos abordados, relacionados ao saneamento, fortalecendo o interesse e mantendo o dialogo interativo, entre todos os participantes.

No dia 21 de Novembro do ano de 2018 foi realizada a atividade de exposição de vídeos educativos, com a temática de Meio ambiente, Saneamento Básico e Transmissão de Doenças, a atividade ocorreu no espaço Clube Atlético dos Pais, que fica na Passagem Vitória, 454 - Terra Firme, com 2h 30min de duração.

A atividade foi composta pela exposição de três vídeos: o primeiro com a temática meio ambiente e duração de aproximadamente 30 minutos, o segundo com a temática saneamento básico com ênfase na importância do saneamento à promoção de saúde da população e o terceiro com a temática transmissão de doenças; durante as reproduções dos vídeos eram realizadas pausas para verificar se o conteúdo estava sendo absorvido pela população além da explicação de alguns termos técnicos citados ao longo da apresentação. Ao fim da exposição dos vídeos os presentes foram convidados a fazerem perguntas para sanar suas dúvidas, e então foi promovida uma roda de conversa sobre os assuntos abordados com a participação de todos, onde notou-se ser satisfatória a participação dos presentes, ficando evidente que o objetivo foi alcançado, que era justamente fazer todos os participantes refletirem sobre os problemas vividos diariamente e interagirem propondo soluções baseadas em tudo que foi abordado no encontro.

\section{Levantamento dos indicadores}

Os melhores dados para serem usados para determinação desses indicadores são os produzidos pelo governo, principalmente pelo Instituto Brasileiro de Geografia e Estatística (IBGE), entretanto, já que os dados necessários para a pesquisa, deveriam ser de uma área delimitada e, que o mesmo instituto só disponibiliza dados de toda a cidade de Belém e não por bairros, por exemplo, foi elaborado um Questionário Socioambiental (anexo B), que servirá de base para o levantamento, principalmente de dados, sobre a 
situação atual dos serviços de saneamento nesta microárea selecionada, que reflete a realidade de grande parte dos moradores locais. A passagem Cabral escolhida como a microárea do estudo está representada na Figura 2.

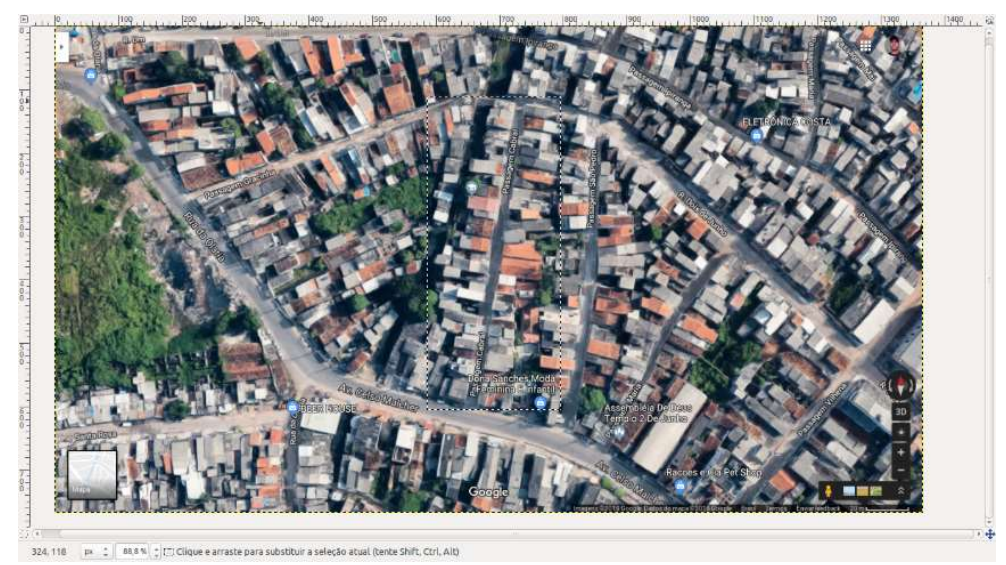

Figura 2: Passagem Cabral. Fonte: Google Maps (2019).

As perguntas do questionário se basearam em situações ligadas ao saneamento ambiental, buscando fazer uma associação das condições de saúde da comunidade estudada com os serviços de saneamento. Com relação ao esgotamento sanitário a situação chega a ser assustadora onde, $100 \%$ dos entrevistados relataram desconhecer a presença de algum tipo de sistema de coleta e/ou tratamento de esgoto; desse modo entende-se que todo o esgoto gerado, ou é jogado diretamente no canal ou na rede de drenagem, quando existente.

Ao analisar as respostas, obtidas por meio do Questionário Socioambiental aplicado na microárea delimitada, relacionadas ao abastecimento de água e tratamento de esgoto esperava-se respostas que revelassem a situação de precariedade vivida pela população, com relação à saúde (ocorrência de doenças), fato este que se confirmou em números expressivos, com as respostas relacionadas a ocorrência de doenças de veiculação hídrica, mostrando o seguinte resultado: a) 80\% dos entrevistados disseram já ter sofrido a ocorrência de algum caso de doença de veiculação hídrica em sua família ou vizinhança; b) deste total citado acima, $60 \%$ relataram que os casos de doenças de veiculação hídrica ocorrem frequentemente; c) $20 \%$ sofrem com frequência média; d) $20 \%$ sofrem com frequência baixa.

Vale ressaltar que dentre os entrevistados, haviam os que não sabiam o que eram as doenças de veiculação hídrica, fato que não gerou surpresa, entretanto, quando isso ocorria, era feita uma rápida explanação sobre o assunto sendo esclarecida as dúvidas apresentadas, e assim as perguntas do questionário, relacionadas as referidas doenças, foram respondidas com mais certeza e correção pelos participantes. A Tabela 1 apresenta os indicadores utilizados na pesquisa, tendo como base o ICSB, para o abastecimento de água, esgotamento sanitário e resíduos sólidos, calculados a partir da porcentagem obtida em pesquisa realizada nos domicílios da microárea selecionada e, sendo classificados como adequados ou inadequados, segundo o ICágua, ICesgoto e IClixo, obedecendo os critérios técnicos pesquisados e observando a relevância que cada indicador desempenha. 
Tabela 1: Indicadores utilizados na pesquisa.

\begin{tabular}{|c|c|c|c|c|}
\hline Atributos & $\begin{array}{l}\text { IC-Índice de } \\
\text { Carência }\end{array}$ & Variáveis & $\begin{array}{l}\text { Porcentagem encontrada } \\
\text { no questionário }\end{array}$ & $\begin{array}{l}\text { Adequada } \\
\text { Inadequada }\end{array}$ \\
\hline \multirow[t]{7}{*}{$\begin{array}{l}\text { Abastecimento de } \\
\text { Água }\end{array}$} & \multirow[t]{7}{*}{0,26} & $\begin{array}{l}\text { Rede geral - canalização em pelo } \\
\text { menos um cômodo }\end{array}$ & 79 & Adequada \\
\hline & & $\begin{array}{l}\text { Rede geral - canalização só na } \\
\text { propriedade ou terreno }\end{array}$ & 10 & Inadequada \\
\hline & & $\begin{array}{l}\text { Poço ou nascente - canalização em } \\
\text { pelo menos um cômodo }\end{array}$ & 5 & Inadequada \\
\hline & & $\begin{array}{l}\text { Poço ou nascente - canalização só na } \\
\text { propriedade ou terreno }\end{array}$ & 2 & Inadequada \\
\hline & & Poço ou nascente - não canalizada & 1 & Inadequada \\
\hline & & $\begin{array}{l}\text { Outra forma - canalização em pelo } \\
\text { menos um cômodo }\end{array}$ & 2 & Inadequada \\
\hline & & $\begin{array}{l}\text { Outra forma - canalização só na } \\
\text { propriedade ou terreno }\end{array}$ & 1 & Inadequada \\
\hline \multirow{6}{*}{$\begin{array}{l}\text { Esgotamento } \\
\text { Sanitário }\end{array}$} & \multirow[t]{6}{*}{9,0} & Rede geral de esgoto ou pluvial & 5 & Adequada \\
\hline & & Fossa séptica & 2 & Inadequada \\
\hline & & Fossa rudimentar & 15 & Inadequada \\
\hline & & Vala & 30 & Inadequada \\
\hline & & Rio ou lago & 40 & Inadequada \\
\hline & & Sem banheiro ou sanitário & 8 & Inadequada \\
\hline \multirow[t]{3}{*}{ Lixo } & \multirow[t]{3}{*}{0,33} & Coletado por serviço de limpeza & 75 & Adequada \\
\hline & & Jogado em rio, lago ou mar & 15 & Inadequada \\
\hline & & Outro destino & 10 & Inadequada \\
\hline
\end{tabular}

Na Tabela 02 foi aplicada a equação 01, e for encontrados os Índices de Carência nos atributos água, esgotamento sanitário e lixo, sendo que depois de calcular a média ponderada atribuindo os pesos 3 para ICágua, 2 para ICesgoto e 1 para IClixo, foi encontrado o valor do Índice de Carência total (ICtotal); valor que foi elevado principalmente devido o valor do ICesgoto, comprovando que a ocorrência de doenças de veiculação hídrica e sua alta frequência está diretamente relacionada a inexistência de um sistema de esgotamento sanitário adequado, a cultura e costumes da população da área bem como a falta de conhecimento, além da baixa renda da maior parte das famílias.

\section{IC = (Valor Observado-10)/(0-100) Equação 1- Cálculo do Índice de Carência.}

Segundo o próprio estudo, "100" corresponde ao pior valor observado (100\% de carência absoluta) e "0" corresponde ao melhor valor ( $0 \%$ de carência). Para a obtenção do índice final que a soma das medias ponderadas de cada um dos índices parciais são atribuídos pesos para cada categoria, sendo eles 3 (ICágua), 2 (ICesgoto) e 1 (IClixo) (CASTRO, 2016).

Tabela 2: Índices de Carência.

\begin{tabular}{ll}
\hline Índice de Carência & Valor \\
\hline ICágua & 0,26 \\
\hline ICesgoto & 19,0 \\
\hline IClixo & 0,33 \\
\hline ICtotal & 6,51 \\
\hline
\end{tabular}

\section{CONCLUSÕES}

A pesquisa nos mostra que a população da bacia hidrográfica do Tucunduba ainda tem muitos desafios a vencer, tendo em vista que falta a conclusão de algumas etapas do projeto para a completa Macrodrenagem da bacia do Tucunduba; existem etapas que sequer foram iniciadas, pois elas só podem começar com a conclusão na sequência prevista no projeto de maneira que uma etapa complemente a outra, 
obedecendo o projeto executivo.

Todavia o levantamento que feito neste trabalho, através dos indicadores de Saneamento e Saúde demonstram que mesmo com o andamento das obras, as ocorrências de doenças de veiculação hídrica continuam a atormentar os moradores da região, colaborando para concluirmos que devem ser intensificadas ações educativas de Saneamento e Saúde na área, para melhorar o conhecimento da comunidade adaptando seus costumes com práticas saudáveis de higiene, como também inserindo atitudes sustentáveis para a formação de cidadãos conscientes do seu papel central na comunidade na contribuição da melhora na qualidade de vida; paralelamente as obras devem ser intensificadas para evitar maiores impactos ao meio ambiente, e assim oferecer um futuro com mais qualidade de vida e bem estar a todos.

Portanto, este trabalho pode contribuir como ferramenta de apoio inicial para o planejamento de políticas públicas voltadas ao bem estar da população e para a educação ambiental, que é de vital importância para que as pessoas obtenham um maior nível de conhecimento sobre seus direitos e deveres, fazendo com que os mesmos se empoderem deste conhecimento, sobre o que é necessário para a promoção qualidade de vida e saúde com sustentabilidade e assim, farão o possível para garantir seus diretos a um meio ambiente mais limpo e saudável para as próximas gerações e, estabelecerão valores sociais, dignidade e participação popular, que são essenciais para o êxito de projetos de infraestrutura aplicados nas áreas das bacias hidrográficas de Belém do Pará.

Foi também muito satisfatória a parceria com a SEDOP, Urbaniza e a CAO Tucunduba, que se mostrou sempre receptiva com nossas solicitações, procurando adequar sua agenda de atividades para estarmos inclusos nas mesmas, onde foi possível facilmente inserir o tema Saneamento/Saúde, e participar ativamente das atividades propostas; sem esquecer também da boa receptividade que os membros da comunidade demonstraram em nossas visitas técnicas e palestras, que serviram para o empoderamento da comunidade local, no que diz respeito a ligação direta que existe entre Saneamento adequado e Saúde.

Entretanto vale salientar que até a presente data o projeto de macrodrenagem na área de estudo ainda não foi completamente finalizado. Vários motivos podem ser elencados, como a demora em convencer os moradores, que tem sua moradia dentro do canal ou na área de abrangência da intervenção de obras de engenharia, a desocuparem os imóveis, prejudicando portanto, o cronograma da obra e, desse modo inviabiliza uma avaliação dos impactos causados pelas obras, como paralelamente os projetos sociais e educativos que estão sendo executados, pois é de suma importância que haja uma comparação dos indicadores de saúde, de antes e depois das obras e projetos citados.

\section{REFERÊNCIAS}

BORJA, P. C.; MORAES, L. R. S.. Indicadores de saúde ambiental com enfoque para a área de saneamento. Nota Técnica, Engenharia Sanitária e Ambiental. Salvador: UFBA 2003.

CASTRO, A. R.. Proposição de Modelo para Cálculo do Índice de Carência em Saneamento Básico - Icsb de uma Região, 2016. Monografia (Bacharelado em Engenharia Ambiental e Sanitária) - Universidade Federal de Goiás, Goiânia, 2016.
CHAVES, A. F. F.; MARTA-COSTA, A. A. V.; TEIXEIRA, L. G.; VALENTE, M. D. R.. Ambiente e saúde: prioridades nos estados da Amazônia Legal. Revista Enciclopédia Biosfera, Goiânia, v.9, n.16, p.2241-2258, 2013.

CRISTO, L. A.; LUZ, L. M.. Morfologia e uso do solo na bacia urbana do Tucunduba, Belém/PA. CIENTífICA: Revista 
brasileira de Geografia Física, v.7, n.3, p.466-475, 2014. DOI:

https://doi.org/10.26848/rbgf.v7.3.p466-475
LUZ, L. M.; RODRIGUES, J. E. C.; CRISTO, L. A.; SILVA, M. D. Estudo geoambiental em bacias urbanas em Belém, PA. Boletim Amazônico de Geografia, Belém, v.01, n.02, p.145160,2014

A CBPC - Companhia Brasileira de Produção Científica (CNPJ: 11.221.422/0001-03) detém os direitos materiais desta publicação. Os direitos referem-se à publicação do trabalho em qualquer parte do mundo, incluindo os direitos às renovações, expansões e disseminações da contribuição, bem como outros direitos subsidiários. Todos os trabalhos publicados eletronicamente poderão posteriormente ser publicados em coletâneas impressas sob coordenação da Sustenere Publishing, da Companhia Brasileira de Produção Científica e seus parceiros autorizados. Os (as) autores (as) preservam os direitos autorais, mas não têm permissão para a publicação da contribuição em outro meio, impresso ou digital, em português ou em tradução. 